\title{
Structural and optical properties of Er implanted AlN thin films: Green and infrared photoluminescence at room temperature
}

\author{
M.J. Soares ${ }^{\text {a,* }}{ }^{\text {, J.P. Leitão }}{ }^{\text {a }}$, M.I.N. da Silva ${ }^{b}$, J.C. González ${ }^{\text {b }}$, F.M. Matinaga ${ }^{\text {b. }}$, K. Lorenz ${ }^{\text {c,d }}$, \\ E. Alves ${ }^{c, d}$, M. Peres ${ }^{a}$, T. Monteiro ${ }^{a}$ \\ a Departamento de Física and I3N, Universidade de Aveiro, 3810193 Aveiro, Portugal \\ bepartamento de Física, Universidade Federal de Minas Gerais, 30123-970 Belo Horizonte, Minas Gerais, Brazil \\ ' Instituto Tecnológico e Nuclear, EN10, 2686-953 Sacavém, Portugal \\ d CFNUL, Av. Prof. Gama Pinto 2, 1649-003 Lisboa, Portugal
}

\section{A R T I C L E I N F O}

\section{Article history:}

Received 29 July 2010

Received in revised form 10 September 2010

Accepted 16 September 2010

\section{Keywords:}

AlN

Raman

RBS

$\mathrm{Er}^{3+}$ photoluminescence

\begin{abstract}
A B S T R A C T
In this work erbium ions were implanted into AlN films grown on sapphire with fluence range: (0.5$2) \times 10^{15} \mathrm{at} / \mathrm{cm}^{-2}$, ion energy range: $150-350 \mathrm{keV}$ and tilt angle: $0^{\circ}, 10^{\circ}, 20^{\circ}, 30^{\circ}$. The optical and structural properties of the films are studied by means of photoluminescence and Raman spectroscopy in combination with Rutherford backscattering/channeling (RBS/C) measurements. The photoluminescence spectra of the $\mathrm{Er}^{3+}$ were recorded in the visible and infrared region between 9 and $300 \mathrm{~K}$ after thermal annealing treatments of the samples. The emission spectrum of the AlN:Er films consists of two series of green lines centered at 538 and $558 \mathrm{~nm}$ with typical $\mathrm{Er}^{3+}$ emission in the infrared at $1.54 \mu \mathrm{m}$. The green lines have been identified as $\mathrm{Er}^{3+}$ transitions from the ${ }^{2} \mathrm{H}_{11 / 2}$ and ${ }^{4} \mathrm{~S}_{3 / 2}$ levels to the ${ }^{4} \mathrm{I}_{15 / 2}$ ground state. Different erbium centers in the matrix are suggested by the change of infrared photoluminescence relative intensity of some of the emission lines when different excitation wavelengths are used. The relative abundances of these centers can be varied by using different implantation parameters. The Raman and RBS/C measurements show good crystalline quality for all the studied films.
\end{abstract}

(c) 2010 Elsevier B.V. All rights reserved.

\section{Introduction}

Infrared (IR) and visible luminescence from rare earth (RE) doped AlN brings significant interest of this material for possible applications in optical communications - IR wavelengths at $1.54 \mu \mathrm{m}$ is coincident with minima in the optical loss of silicabased glass fibers utilized in telecommunications - and full color displays [1]. AlN with its large band gap allows energetically high lying RE levels to be exploited and thermal quenching of the luminescence is expected to be small [2-5].

Ion implantation is a very attractive technological tool for device fabrication steps such as selective-area doping, electrical isolation, etc. However, in all of these fabrication steps, limitations may arise due to ion-beam-produced lattice disorder and its undesirable consequences [6]. In this work a set of AlN samples were implanted with different fluencies of $\mathrm{Er}^{3+}$ ions, ion energies and tilt angles. The as-implanted samples were further submitted to thermal annealing treatments to optically activate the $\mathrm{Er}^{3+}$ ions and visible and infrared intraionic luminescence was measured. Surface, lattice damage and the lattice location of the implanted ions

\footnotetext{
* Corresponding author. Tel.: +351 234370 200; fax: +351 234378197.

E-mail address: jorgesoares@ua.pt (M.J. Soares).
}

were characterized by Raman spectroscopy, Rutherford backscattering/channeling (RBS/C) and correlated to the optical properties of the samples measured by photoluminescence.

\section{Experimental}

AlN films with thickness of $3 \mu \mathrm{m}$ grown by hydride vapor phase epitaxy (HVPE) on sapphire substrates purchased from TDI. The AlN films were implanted with $\mathrm{Er}^{3+}$ ions with a fluence range: $(0.5-2) \times 10^{15} \mathrm{at} / \mathrm{cm}^{-2}$, ion energy range: $150-350 \mathrm{keV}$ and tilt angle between the ion beam and the surface normal: $0^{\circ}, 10^{\circ}, 20^{\circ}$, $30^{\circ}$. After the implantation the samples were annealed during $20 \mathrm{~min}$ at temperatures up to $1300^{\circ} \mathrm{C}$ in a conventional tube furnace with an overpressure of $4 \times 10^{5} \mathrm{~Pa}$ nitrogen gas. RBS/C measurements were performed with $2.0 \mathrm{MeV} \mathrm{He}^{+}$ions and the backscattered particles were detected with solid state detectors at $140^{\circ}$ and close to $180^{\circ}$. Steady state infrared photoluminescence

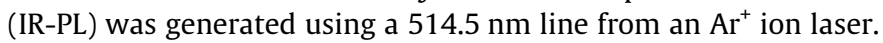
The samples were placed on a cold finger of a continuous flow cryostat in vacuum and the sample temperature could be controlled in the range from $5 \mathrm{~K}$ up to room temperature (RT). The IR-PL was measured using a Bruker $66 \mathrm{~V}$ Fourier transform spectrometer equipped with a liquid nitrogen cooled germanium 
detector. Steady state visible photoluminescence (VIS-PL) was carried out between $9 \mathrm{~K}$ and RT. The excitation source was the $514.5 \mathrm{~nm}$ line of an $\mathrm{Ar}^{+}$ion laser. The luminescence was measured using a JobinYvon T64000 spectrometer equipped with a liquid nitrogen cooled CCD. Raman spectroscopy was performed with a LabRam HR and T64 000 spectrometers and the excitation sources were the 325 and $514.5 \mathrm{~nm}$ lines of $\mathrm{HeCd}$ and $\mathrm{Ar}^{+}$lasers, respectively.
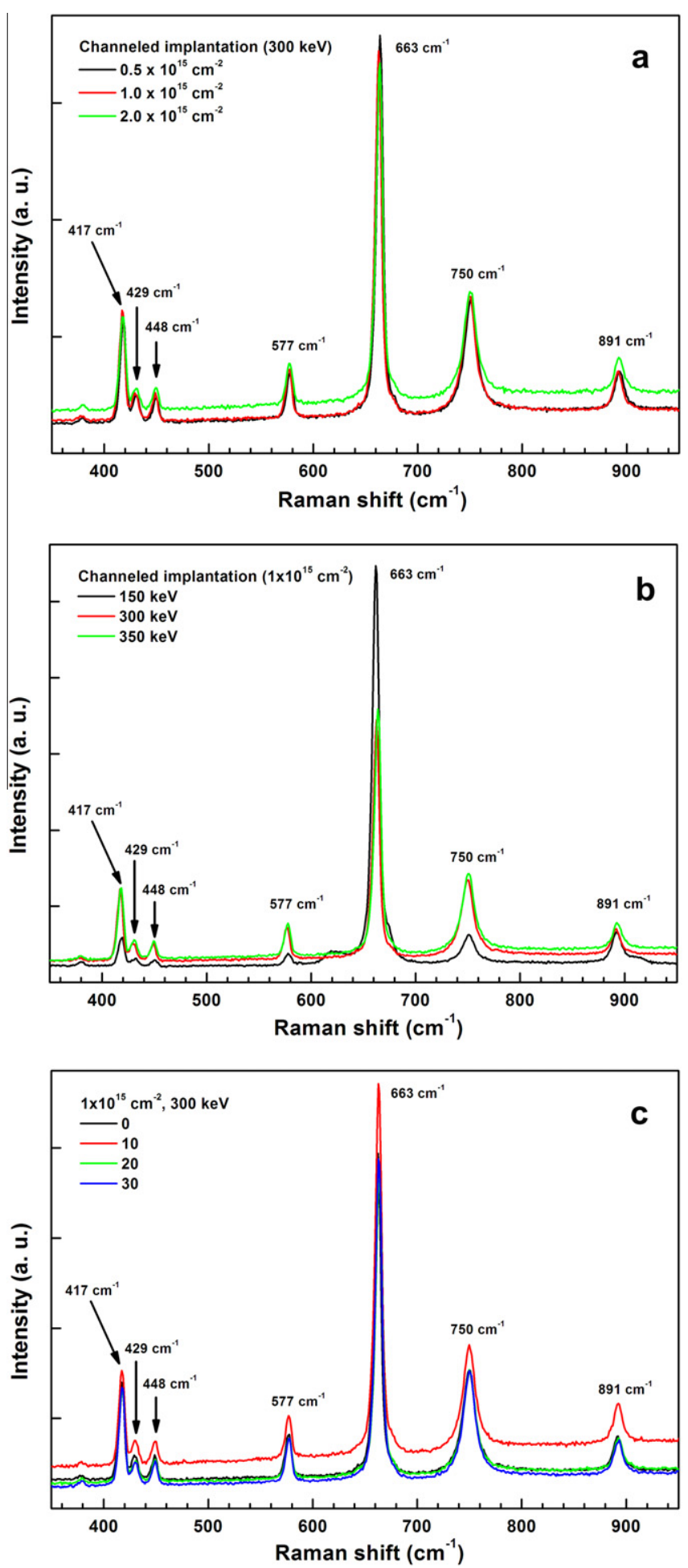

Fig. 1. Raman spectra of the films as a function of $\mathrm{Er}^{3+}$ ions implanted parameters: fluence range: $(0.5-2) \times 10^{15} \mathrm{at} / \mathrm{cm}^{-2}(\mathrm{a})$, ion energy range: $150-350 \mathrm{keV}$ (b) and tilt angle: $0^{\circ}, 10^{\circ}, 20^{\circ}, 30^{\circ}(\mathrm{c})$

\section{Results and discussion}

The Fig. 1 shows the Raman spectra of the films as a function of $\mathrm{Er}^{3+}$ ion implantation parameters: fluence range of $(0.5-2) \times$ $10^{15} \mathrm{at} / \mathrm{cm}^{-2}$ (a), ion energy range of $150-350 \mathrm{keV}(\mathrm{b})$ and tilt angle of $0^{\circ}, 10^{\circ}, 20^{\circ}, 30^{\circ}$ (c). The peaks at $\sim 660 \mathrm{~cm}$ and $890 \mathrm{~cm}^{-1}$ with full width at half maximum of $\sim 7$ and $\sim 10 \mathrm{~cm}^{-1}$, respectively, are attributed to the $\mathrm{E}_{2}(\mathrm{TO})$ and $\mathrm{A}_{1}(\mathrm{LO}) \mathrm{AlN}$ phonon modes. These are allowed by the Raman selection rules for the backscattering geometry $[Z(x, x)-Z]$ used in the experiment [7]. The peaks at $417,429,448,577,750 \mathrm{~cm}^{-1}$ are attributed to phonon modes from the sapphire substrate. The observed phonon mode energies are close to the values measured for the AlN bulk [8,9] which show good crystalline quality for all the studied films. RBS/C random and $\langle 00001\rangle$ aligned spectra (not shown) clearly proof a strong reduction of implantation damage when the implantation is performed in channeled geometry along the $c$-axis (0 tilt) as previously reported for Eu-implantation [10]. Fig. 2 presents full angular scans across the $\left\langle\begin{array}{lllll}0 & 0 & 1\end{array}\right\rangle$ and the tilted $\langle\overline{2} 113\rangle$ axes for samples implanted with $1 \times 10^{15} \mathrm{at} / \mathrm{cm}^{2}$ along the $c$-axis (Fig. 2a and b) and tilted by $10^{\circ}$ (Fig. $2 \mathrm{c}$ and d). For the sample implanted without tilt an almost complete overlap of the scans for $\mathrm{Al}$ and $\mathrm{Er}$ are observed for both crystal directions showing that $\mathrm{Er}$ is incorporated on substitutional Al-sites. For the tilted implantation, on the other hand, a clear narrowing of the Er-scan, in particular for the $\langle\overline{2} 113\rangle$ axis, reveals a displacement of Er from the substitutional site possibly due to an interaction of Er with implantation defects. Furthermore, the near substitutional fraction is slightly lower as seen in the increased minimum yields for Er.

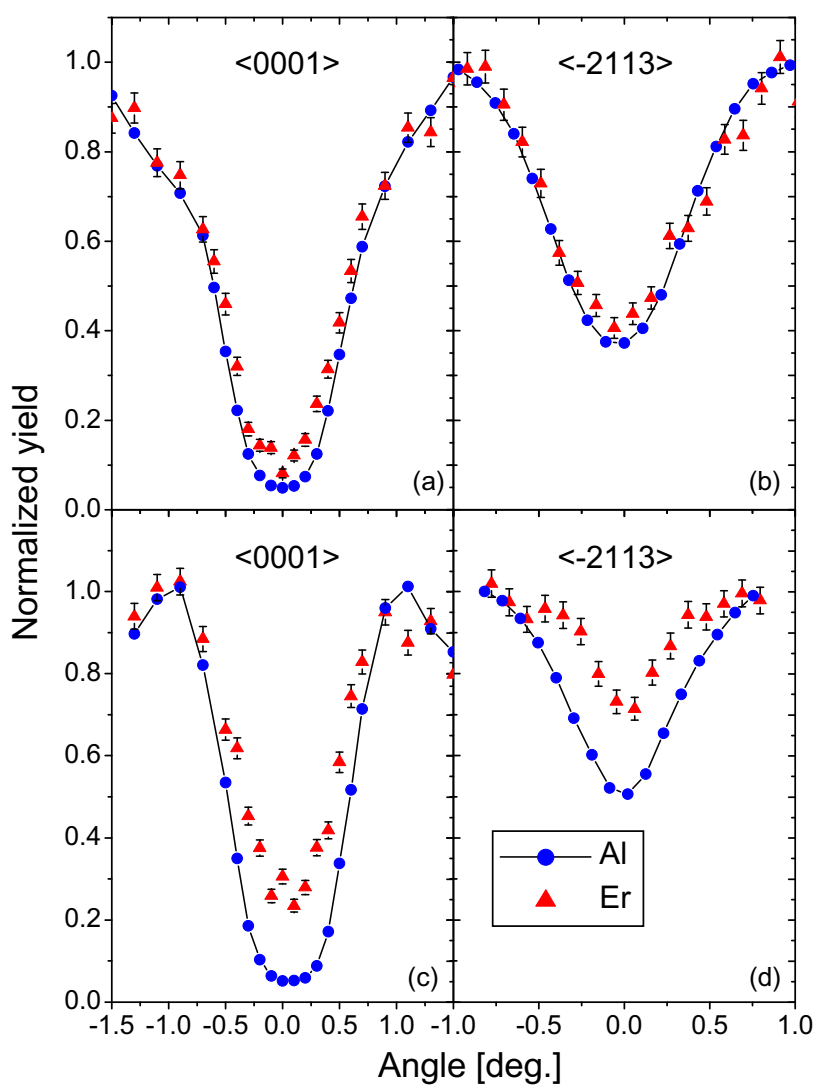

Fig. 2. Channeling scans for the $\left\langle\begin{array}{lllll}0 & 0 & 0 & 1\end{array}\right\rangle$ and $\langle\overline{2} 113\rangle$ crystal directions for the AlN sample implanted with a fluence of $1 \times 10^{15} \mathrm{Er} / \mathrm{cm}^{2}$ directly after implantation with $0^{\circ}$ tilt $(\mathrm{a}+\mathrm{b})$ and $10^{\circ}$ tilt $(\mathrm{c}+\mathrm{d})$. 

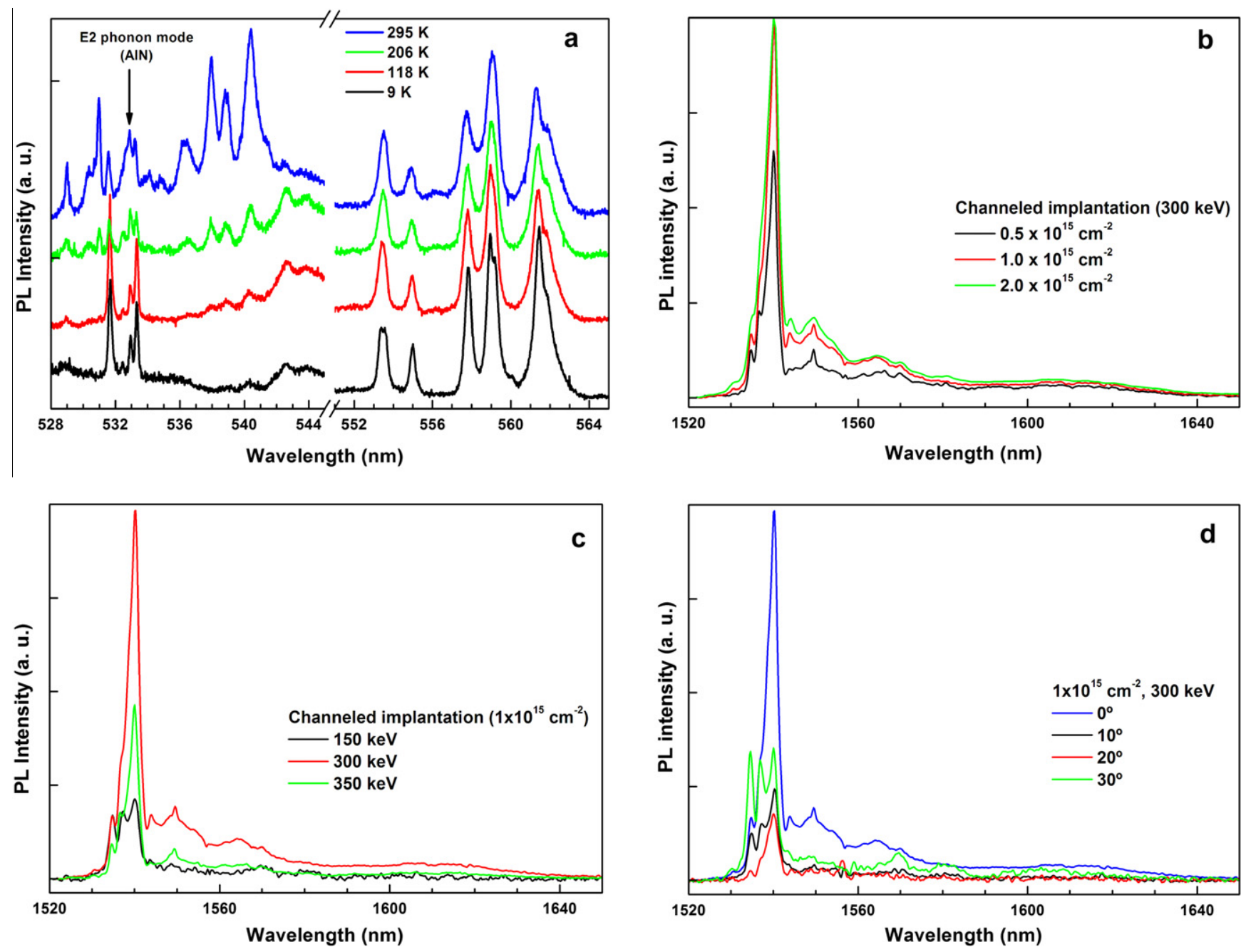

Fig. 3. (a) Visible $\mathrm{Er}^{3+}$ luminescence as a function of temperature and (b-d) $10 \mathrm{~K}$ infrared PL as a function of the implantation parameters.

Fig. 3 shows the PL characterization in the visible and infrared spectral range of the AlN samples implanted with different fluencies, ion energies and tilt angles. The samples luminescence was obtained with excitation $(514.5 \mathrm{~nm})$ below the AlN band gap. This excitation wavelength is close to an intra $4 \mathrm{f} \mathrm{Er}^{3+}$ absorption line $\left({ }^{4} \mathrm{I}_{15 / 2} \rightarrow{ }^{4} \mathrm{~F}_{7 / 2}\right)$ leading to resonant excitation of the $\mathrm{Er}^{3+}$ ions [2].

Fig. 3a shows the temperature dependent PL of the AlN:Er sample obtained with below band gap excitation $(514.5 \mathrm{~nm})$. Two sets of sharp lines centered at $\sim 538 \mathrm{~nm}$ and the other at $\sim 558 \mathrm{~nm}$ could be identified and assigned to transitions from the excited state multiplets ${ }^{2} \mathrm{H}_{11 / 2}$ and ${ }^{4} \mathrm{~S}_{3 / 2}$ to the fundamental one ${ }^{4} \mathrm{I}_{15 / 2}$, respectively. The lines at lower temperature arise from the phonon modes in the sapphire substrate and the $\mathrm{E}_{2}$ (TO) mode in AlN. As the temperature is increased, the intensity of the transitions ${ }^{4} \mathrm{~S}_{3 / 2} \rightarrow{ }^{4} \mathrm{I}_{15 / 2}$ slightly decreases whereas a new thermally populated set of lines, centered at $\sim 538 \mathrm{~nm}$, appears. This temperature dependent PL was observed from Er doped GaN samples prepared by metalorganic molecular beam epitaxy (MOMBE) $[11,12]$. Visible luminescence from $\mathrm{Er}^{3+}$ ions was reported in an earlier work by using cathodoluminescence [13]. In this case the excitation is always performed above the AlN bandgap as well as by direct impact. Up to our knowledge, visible PL from $\mathrm{Er}^{3+}$ was reported from AlN:Er films and nanostructures grown by magnetron sputtering $[14,15]$ but in implanted samples with $\mathrm{Er}^{3+}$ ions this is the first time.
In the range 1530-1545 $\mathrm{nm}$, corresponding to the transition between the ${ }^{4} I_{13 / 2}$ multiplet lowest excited state to the ${ }^{4} I_{15 / 2}$ multiplet ground at least three sharp lines are observed which suggest the presence of different optical centers due to different neighborhoods of the $\mathrm{Er}^{3+}$ ion [16]. In fact, the relative intensity of the three lines in the above range is critically influenced by the used implantation energy and the tilt angle (Fig. $3 \mathrm{c}$ and d) and in minor extend by the implantation fluence (Fig. 3b). These findings are in good agreement with the RBS/C scans that suggest that for tilted implantation $\mathrm{Er}$ is interacting with lattice defects that cause a displacement of the ion. Different optically active centers may therefore correspond to undisturbed substitutional Er and to Er coupled to defects that change the symmetry of its microscopic environment. As seen from Fig. 3(b-d), the implantation parameters that maximize the PL intensity around the $1.54 \mu \mathrm{m}$ in the studied samples correspond to implantation energy of $300 \mathrm{keV}$, fluence range (12 ) $\times 10^{15} \mathrm{~cm}^{-2}$ and a tilt angle of $0^{\circ}$.

\section{Conclusions}

The Er implantation in AlN resulted in the formation of more than one optical center. Evidence for a good recovery of the lattice was found for all implantation parameters considered in this work. RBS/channeling measurements showed the presence of Er atoms in substitutional positions when the implantation was carried out 
along the $c$-axis and displaced from the substitutional site for tilted implantation. In addition to the infrared emission from the ${ }^{4} \mathrm{I}_{13 / 2}$ multiplet lowest excited state to the ${ }^{4} \mathrm{I}_{15 / 2}$ multiplet ground state, the large band gap of the AlN allowed the observation of visible intraionic photoluminescence. In the former at least three sharp lines were observed in the $1530-1545 \mathrm{~nm}$ range and its dependence on excitation energy suggests the presence of different optical centers related to the $\mathrm{Er}^{3+}$ ion. The relative abundance of these centers can be influenced by the implantation angle in good agreement with RBS/C results showing changes in the Er incorporation sites for different implantation geometries. In the visible range transitions from the lowest excited state multiplets ${ }^{2} \mathrm{H}_{11 / 2}$ and ${ }^{4} \mathrm{~S}_{3 / 2}$ to the fundamental one ${ }^{4} \mathrm{I}_{15 / 2}$ were detected.

\section{Acknowledgements}

The authors acknowledge the project PTDC/CTM/100756/2008. M. Peres thank the financial support of the Fundação para a Ciência e Tecnologia (FCT), through the PhD Grant SFRH/BD/45774/2008. The authors also acknowledge the financial support of the Portuguese Agency GRICES as well as the Brazilian Agency CAPES, through the Grant 172/07.

\section{References}

[1] J. Ballato, J.S. Lewis III, P. Holloway, MRS Bull. 24 (1999) 51.

[2] A.J. Neuhalfen, B.W. Wessels, Appl. Phys. Lett. 60 (1992) 2657.

[3] G.H. Dieke, H.M. Crosswhite, Appl. Opt. 2 (1963) 675.

[4] M. Zavada, D. Zhang, Solid-State Electron. 38 (1995) 1285.

[5] V.I. Demitrova, P.G. Van Patten, H.H. Richardson, M.E. Kordesch, Appl. Phys. Lett. 77 (2000) 478.

[6] S.O. Kucheyev, J.S. Williams, J. Zou, C. Jagadish, M. Pophristic, S. Guo, I.T Ferguson, M.O. Manasreh, J. Appl. Phys. 92 (2002) 3554.

[7] E. Ruiz, S. Alvarez, P. Alemany, Phys. Rev. B 49 (1994) 7115.

[8] M. Kuball, Surf. Interface Anal. 31 (2001) 987.

[9] P. Perlin, A. Polian, T. Suski, Phys. Rev. B 47 (1993) 2874.

[10] K. Lorenz, E. Alves, F. Gloux, P. Ruterana, M. Peres, A.J. Neves, T. Monteiro, J. Appl. Phys. 107 (2010) 023525.

[11] R. Birkhahn, R. Hudgnins, D. Lee, A.J. Steckl, R.J. Molnar, A. Saleh, J.M. Zavada, J. Vac. Sci. Tchnol. B 17 (3) (1999) 1195 (3 May/June).

[12] U. Hommerich, J.T. Seo, C.R. Abernathy, A.J. Steckl, J.M. Zavada, Mater. Sci. Eng. B 81 (2001) 116-120.

[13] V.I. Dimitrova, F. Perjeru, H. Chen, M.E. Kordesch, Mater. Res. Soc. Proc. 621 (2000) Q5.41.

[14] F.S. Liu, Q.L. Liu, J.K. Liang, J. Luo, H.R. Zhang, Y. Zhang, B.J. Sun, G.H. Rao, J. Appl Phys. 99 (2006) 053515.

[15] V. Brien, M. Dossot, H. Rinnert, S.S. Hussain, B. Humbert, P. Pigeat, Mater Res. Soc. Symp. Proc., 1111@, 2009, Materials Research Society, 1111-D0203.

[16] K. Lorenz, E. Alves, T. Monteiro, M.J. Soares, M. Peres, P.J.M. Smulders, Nucl. Instrum. Methods Phys. Res. B 242 (2006) 307. 